\title{
Enunciados possíveis: um exercício sobre minorias e ethos discursivo
}

DOl: http://dx.doi.org/10.21165/el.v48i3.2180

\section{Ana Elisa Sobral Caetano da Silva Ferreira'}

\section{Resumo}

Tendo a Análise de Discurso (AD) Francesa como campo teórico-metodológico, analisaremos o breve corpus deste exercício, composto por enunciados que apresentam marcas da construção de um ethos visado, no posicionamento do sujeito discursivo e como esse processo se relaciona com a cristalização do sintagma lugar de fala (SALGADO; GATTI, 2018). Propomos uma reflexão sobre a validação dos discursos que circulam dentro de determinadas comunidades discursivas (MAINGUENEAU, 2008a) entendidas como minorias e aparentemente amalgamadas. Para tanto, mobilizaremos conceitos fundamentais da $A D$, tais como, memória discursiva e interdiscurso (PECHÊUX, 2016) na manutenção do imaginário de homogeneização dessas comunidades.

Palavras-chave: ethos discursivo; comunidade discursiva; preconceito.

1 Instituto Federal de São Paulo (IFPS), Cubatão, São Paulo, Brasil; anaelisaferreira@me.com; https://orcid.org/0000-0003-4633-632X 


\title{
Possible statements: an analysis exercise on minorities and discursive ethos
}

\begin{abstract}
Using the French Discourse Analysis (DA) as the theoretical-methodological field, we will analyze the brief corpus of this exercise, composed by statements that present marks of the construction of a targeted ethos, in the positioning of the discursive subject and how this process is related to the crystallization of the phrase lugar de fala (place of speech) (SALGADO; GATTI, 2018). We propose a reflection on the validation of the discourses that circulate within certain discursive communities (MAINGUENEAU, 2008a) understood as minorities and apparently amalgamated. Therefore, we will mobilize fundamental concepts of DA, such as discursive memory and interdiscourse (PECHÊUX, 2016) in the maintenance of the imaginary homogenization of these communities.
\end{abstract}

Keywords: discursive ethos; discursive commutity; prejudice.

\section{Introdução: conceitos para possíveis discursos}

"A memória irrompe na atualidade do acontecimento."

(COURTINE, 2009, p. 103)

O que venho propor neste artigo é um exercício de análise no qual discutiremos alguns conceitos fundamentais da Análise de Discurso (AD) Francesa para refletir sobre "a marca do inconsciente como 'discurso do Outro'" (PÊCHEUX, 2016, p. 159). Procuramos entender como se dá o processo de tomada de posição do sujeito em discursos que circulam em comunidades distintas - que, a princípio, parecem amalgamadas - e como o enunciador, ao visar um ethos discursivo, corrobora a manutenção do imaginário de homogeneização dessas comunidades.

Considerando nosso recorte histórico, em que movimentos como Black lives matter, Nenhuma a menos e $M e$ too ${ }^{2}$ estão entre os assuntos mais discutidos em redes sociais como Twitter, o debate sobre posicionamento do enunciador, cristalizado no sintagma lugar de fala, e questões relacionadas a grupos, denominados minoritários, é extremamente profícuo e ao mesmo tempo polêmico.

2 Segundo levantamento disponível em: https://www.pewinternet.org/2018/07/11/an-analysisof-blacklivesmatter-and-other-twitter-hashtags-related-to-political-or-social-issues/. Acesso em: 04 set. 2019. 
O discurso politicamente correto pode ser visto como uma forma de censura ou como um espaço de resistência, mas é inegável que tenha apresentado desdobramentos sociais e políticos, que perpassam inevitavelmente a linguagem (cf. POSSENTI, 1995).

Um dos conceitos da Análise do Discurso (AD) que contribui para analisarmos como esses desdobramentos estão marcados na linguagem é a definição de ethos discursivo sugerida por Maingueneau (2008a, p. 60): "Cada tomada de palavra implica, ao mesmo tempo, levar em conta representações que os parceiros fazem um do outro e a estratégia de fala de um locutor que orienta o discurso de forma a sugerir através dele certa identidade".

Portanto, se o enunciador procura mobilizar alguns padrões estabilizados na memória discursiva para atingir o ethos visado, ele faz circular "formulações anteriores, já enunciadas" (COURTINE, 2009, p. 104) e é nesse sentido que a memória discursiva "diz respeito à existência histórica do enunciado no interior de práticas discursivas regradas por aparelhos ideológicos" (COURTINE, 2009, p. 104, grifo nosso).

O autor ressalta que o conceito de memória nos estudos do discurso não é o mesmo que a memorização psicológica. Essa definição é fundamental para entendermos os efeitos da memória como práticas que permitem certos dizeres.

Para Pêcheux (2014, p. 150), "o sujeito se constitui pelo esquecimento daquilo que o determina", mas o processo discursivo - "o sistema de relações de substituição, paráfrases, sinonímias etc. que funcionam entre os elementos linguísticos" (PÊCHEUX, 2014, p. 148) - coloca em funcionamento o interdiscurso que "disponibiliza dizeres que afetam o modo como o sujeito significa em uma situação discursiva dada" (ORLANDI, 2015, p. 29). Tomemos o futebol como espaço para esse processo de formulação do dizível $^{3}$ em questões que discutem racismo e homofobia, sabendo que a história desse esporte é marcada por inúmeros casos de discriminação contra negros ${ }^{4}$ e homossexuais.

O enunciado, figura 1, adiante, que desencadeou este exercício permite repensarmos um ethos já estabilizado correspondente a ser homem em uma cena validada que evoca

3 "A constituição determina a formulação, pois só podemos dizer (formular) se nos colocamos na perspectiva do dizível (interdiscurso, memória). Todo dizer, na realidade, se encontra na confluência de dois eixos: o da memória (constituição) e o da atualidade (formulação)." (ORLANDI, 2015, p. 31).

4 Mario Filho (2010, p. 69) debate a questão racial em seu livro o negro no futebol brasileiro, citando como exemplo o caso do jogador Carlos Alberto que utilizava pó de arroz para clarear a pele antes de entrar em campo, e destaca a discriminação contra negros na passagem "Preto só entrava no scratch uma vez na vida e outra na morte... Cada lugar do scratch tinha um dono: branco de boa família. A superioridade de raça: da raça branca sobre a raça preta; a superioridade de classe: da classe alta sobre a classe média, da classe média sobre a classe baixa. 
determinados estereótipos. Para Maingueneau (2008a), essas cenas já estão instaladas na memória coletiva, reforçando ou refutando determinados modelos.

Tendo o futebol como uma instituição (BANDEIRA; SEFFNER, 2013) que permite a produção, a circulação e a hierarquização dos discursos referentes à masculinidade, entendemos que o estádio, aqui sendo a cena validada, projeta o enunciador como torcedor, evocando certas características que são associadas a determinados times.

Assim como o torcedor palmeirense é relacionado ao porco e o corintiano ao gambá, o torcedor são-paulino éamplamente vinculado àfıgura do veado, entretanto, diferentemente dos outros animais citados, a imagem do veado no Brasil é ligada à homossexualidade (designada com a variante homófona "viado"), permitindo que se instaure uma polêmica nos discursos produzidos sobre masculinidade dentro do futebol. Para Maingueneau (2008b, p. 113), "Poderíamos dizer que a polêmica é necessária porque, sem essa relação com o Outro, sem essa falta que torna possível sua própria completude, a identidade do discurso correria o risco de se desfazer".

Ao observarmos o enunciado abaixo, notamos o funcionamento da manutenção de sentido na tomada de posição do sujeito discursivo.

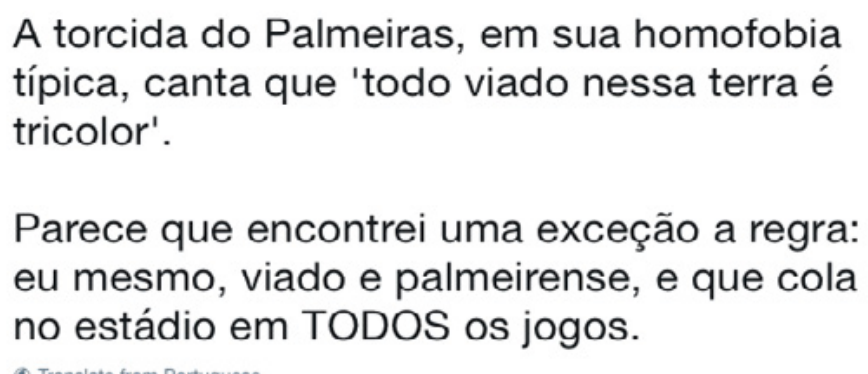

(6) Translate from Portuguese

Figura 1. Reprodução

Fonte: http://bit.ly/33S1XmZ. Acesso em: 03 set. 2019

Essa articulação, correspondente ao retorno do Universal no sujeito (PECHÊUX, 2016), faz a manutenção do interdiscurso, associando a imagem do tricolor (torcedor do São Paulo) à homossexualidade. Entretanto, a tomada de posição do sujeito-falante propõe uma quebra nesse já-dito ${ }^{5}$

5 A forma-sujeito (pela qual o "sujeito do discurso" se identifica com a formação discursiva que o constitui) tende a absorver-esquecer o interdiscurso no intradiscurso, isto é, ela simula o interdiscurso, de modo que o interdiscurso aparece como o puro "já-dito" do intra-discurso, no qual ele se articula por "co-referência." (PECHÊUX, 2016, p. 154). 
Ao se posicionar como viado e palmeirense, o enunciador convoca a posição do sujeito enquanto sujeito-falante (PECHÊUX, 2016) que pode ser lida não como "ato originário", já que deve ser "compreendida como o efeito, na forma-sujeito, da determinação do interdiscurso como discurso-transverso, isto é, o efeito da "exterioridade" (PECHÊUX, 2016, p. 160), mas como uma retomada a discursos de afırmação que circulam em comunidades discursivas específicas (MAINGUENEAU, 2008a), em especial àquelas que se identificam como minorias.

Para Salgado e Gatti (2018), a convocação de um "lugar de fala" permite a retomada de vetores semânticos específicos, que, em dada conjuntura sócio-histórica, funcionam como um referente social, já que o posicionamento do enunciador serve como legitimação do que é dito. Ao enunciar "eu mesmo", o torcedor palmeirense convoca esse lugar de legitimação, próprio do ethos discursivo visado. O sintagma "lugar de fala" é, segundo os autores, "uma expressão que aparece em contextos discursivos antidiscriminatórios, afırmativos da pluralidade e do direito à diferença" (SALGADO; GATTI, 2018, p. 573).

O posicionamento do enunciador surge nesse contexto antidiscriminatório, que só é possível dado o recorte histórico que permite que isso seja dito segundo a definição de formação discursiva (FD) ${ }^{6}$. No caso do enunciado na figura 1, o que pode e deve ser dito por esse sujeito está na forma de um tuíte, gênero com suas peculiaridades e que circula dentro de uma rede social digital (Twitter) de amplo alcance.

Entre essas peculiaridades está a possibilidade de atingir uma gama de interlocutores que não era inicialmente visada, já que o mídium se torna determinante para que o discurso se constitua (MESTI; BARONAS, 2019). Um perfil público, nessa rede, permite que todos os usuários que façam uma busca por palavras-chaves como "Palmeiras" ou "homofobia" encontrem o tuíte acima citado. Sabendo que,

Desde que haja enunciação, alguma coisa da ordem do ethos se encontra liberada: por meio de sua fala, um locutor ativa no intérprete a construção de determinada representação de si mesmo, pondo em risco o domínio da sua própria fala; é-lhe necessário, então, tentar controlar, mais ou menos confusamente, o tratamento interpretativo dos signos que ele produz. (MAINGUENEAU, 2008a, p. 73).

Considerar onde esse enunciado circula e sua abrangência é essencial para que entendamos esse complexo processo de construção do ethos em plataformas digitais, já que essa imagem não cabe apenas àquele que enuncia, mas trata-se de um jogo de

6 "Numa formação ideológica dada, isto é, a partir de uma posição dada numa conjuntura dada, determinada pelo estado da luta de classes, determina o que pode e deve ser dito (articulado na forma de uma arenga, de um sermão, de um panfleto, etc.)" (PECHÊUX, 2016, p. 147, grifo do autor). 
reconstrução entre o já-dito e a memória em um espaço de largo alcance, no qual a interação apresenta aspectos diacrônicos e sincrônicos.

\section{Jogo é jogo. Pode tudo?}

Não, não pode. Segundo Pêcheux (2016), somos limitados por aquilo que pode e deve ser dito, e que esses dizeres são geridos por uma função que Maingueneau (2008a, p. 38) denomina de archeion: "O archeion associa assim intimamente o trabalho de fundação no e pelo discurso, a determinação de um lugar associado a um corpo de enunciadores consagrados e a uma gestão de memória.".

Somos regulados por discursos que nos antecedem e nos atravessam. Esses discursos são geridos por fontes que os legitimam e proferidos por sujeitos autorizados. 0 discurso relacionado às minorias é atravessado, por exemplo, pela lei e pela ciência, que determinam como a sociedade deve agir/reagir em uma determinada conjuntura histórica.

Para esse exercício, entenderemos a ciência como discurso constituinte:

O discurso constituinte implica assim um tipo de ligação específica entre operações linguageiras e o espaço institucional. As formas enunciativas não são aí um simples vetor de ideias, elas representam a instituição no discurso, ao mesmo tempo em que moldam, legitimando esse universo social no qual elas vêm se inscrever. (MAINGUENEAU, 2008b, p. 54).

Mas, também consideraremos a representatividade da lei na legitimação de discursos e práticas ao moldar o universo social no qual ela se inscreve. A análise do enunciado, a seguir, proferido pelo comentarista Walter Casagrande Junior aponta como mudanças na ciência e, por consequência, na lei não garantem a circulação do discurso legitimado pelas instituições (a homossexualidade como prática afetiva e sexual), mas sim aquele sedimentado em determinada conjuntura histórica; a homossexualidade como doença.

O programa de televisão "Seleção SporTV", exibido no dia 09 de março de 20187, teve como convidados os comentaristas esportivos Walter Casagrande Junior e Paulo César Vasconcelos, entre outros, para comentar o tuíte ${ }^{8}$ (figura 1) acima citado.

7 Disponível em: https://sportv.globo.com/site/programas/selecao-sportv/noticia/a-reacaopositiva-foi-muito-maior-diz-torcedor-do-palmeiras-que-reclama-de-homofobia-nos-estadios. ghtml. Acesso em: 02 set. 2019.

8 Disponível em: https://twitter.com/delucca/status/971901780526272512. Acesso em: 02 set. 2019. 
O debate sobre temas como racismo e preconceito sexual não é estranho a esse esporte. O depoimento dado por Walter Casagrande Junior ("Eu sei muito bem o que esse rapaz sofre de outra maneira, mas o preconceito é o mesmo. A linha de preconceito para homossexual, para negro, racismo para negro e para dependente químico é a mesma coisa, dói do mesmo jeito") aponta questões que se relacionam aos conceitos acima debatidos, fundamentais para a AD, que podem explicar a associação que o comentarista faz entre dependência química, homossexualidade e raça.

Assim como o torcedor palmeirense, Casagrande também convoca um lugar ("eu sei muito bem") na construção do ethos discursivo visado. Entretanto, esse lugar não pode ser considerado o mesmo do primeiro enunciado. Apesar de doer do mesmo jeito, esses discursos são validados por instituições que se inscrevem no universo social de formas distintas.

A ciência produz seus próprios regulamentos que são historicamente determinados de acordo com os paradigmas científicos de cada época, como é o caso da Classificação Estatística Internacional de Doenças e Problemas Relacionados com a Saúde, que até 1977 considerava a homossexualidade como transtorno mental:

Em nosso país, foi apenas na década de 80 que o Conselho Federal de Medicina tornou sem efeito o código 302.0 da Classificação Internacional de Doenças (CID), deixando de considerar a homossexualidade como uma categoria de desvios e transtornos sexuais. Já o Conselho Federal de Psicologia pronunciouse oficialmente em 1999, por meio da Resolução CFP 01/99, definindo como antiética a postura de psicólogos que tratam a homossexualidade como desvio comportamental ou doença. No cenário mundial, nessa mesma época, a Organização Mundial de Saúde também repudiou a conotação de doença dessa prática afetiva e sexual. (PALMA; LEVANDOWISK, 2008, p. 773).

Já a dependência química ainda é prevista na CID 10 entre os grupos F10 e F19 que tratam sobre transtornos mentais e comportamentais devidos ao uso de substância psicoativa.

Compreendemos então a força do tempo histórico na manutenção de sentidos e o funcionamento das instituições na legitimação dos discursos. Apesar da remoção da homossexualidade da Classificação, no final da década de 70, alguns efeitos desse discurso ainda se fazem presentes hoje, demonstrando que a ciência apenas não foi capaz de deslegitimar o discurso da homofobia como doença, entretanto, a criminalização da homofobia talvez funcione como esta ligação específica entre operações linguageiras e o espaço institucional, moldando e legitimando novos dizeres. 
Observamos um percurso semelhante quanto à questão racial, legitimada no discurso pela ciência e inscrita em práticas sociais por meio da lei, entretanto, tal semelhança não garante que os discursos circulem da mesma forma e tenham os mesmos desdobramentos.

Quando Casagrande enuncia que "A linha de preconceito para homossexual, para negro, racismo para negro e para dependente químico é a mesma coisa, dói do mesmo jeito" (transcrição), percebemos que a palavra racismo é utilizada no lugar de preconceito e esse fato pode ser analisado como uma substituição por equivalência (PECHÊUX, 2016), reforçando a ideia de que os preconceitos tenham origem semelhante ou sejam intercambiáveis. No enunciado de Casagrande, o racismo é tido como uma maneira de generalização de preconceito contra minorias.

Nesse sentido, a fala do comentarista mobiliza os dizeres anteriormente sedimentados, discursos transversos que aparecem no fio do discurso que ele atualiza, aproximando preconceitos de diferentes ordens e que são atravessados pela história de maneira singular.

É possível afirmar que os discursos daqueles que se filiam a minorias distintas são os mesmos? Negros, homossexuais e dependentes químicos podem convocar memórias discursivas afins e construir ethe discursivos semelhantes porque sofrem preconceito ou as FD de cada grupo têm suas próprias características e, apesar de compartilharem algumas semelhanças, são comunidades discursivas diferentes?

Entendemos que a produção que circula nas comunidades discursivas "é cimentada por discursos que são produto dessa mesma comunidade." (MAINGUENEAU, 2008a, p. 45), portanto, as normas e os ritos que regem a produção dos discursos enunciados por homossexuais ou negros, por exemplo, são distintos.

\section{Quem fala? 0 ethos visado e o ethos produzido}

Foucault (2008, p. 56), em Arqueologia do Saber, inicia o $4^{\circ}$ capítulo (A formação das modalidades enunciativas) propondo uma reflexão sobre sujeitos falantes e seu status:

Quem fala? Quem, no conjunto de todos sujeitos falantes, tem boas razões para ter esta espécie de linguagem? Quem é seu titular? Quem recebe dela sua singularidade, seus encantos, e de quem, em troca, recebe, se não sua garantia, pelo menos a presunção de que é verdadeira? Qual é o status dos indivíduos que têm - e apenas eles - o direito regulamentar ou tradicional, juridicamente definido ou espontaneamente aceito, de proferir semelhante discurso? 
Foucault (2008) cita a figura do médico - estabilizada por seu diploma e reconhecida socialmente-, porém, o que nos interessa aqui é o status espontaneamente aceito, ou aquele que parece surgir das características ou experiências do enunciador. Tais características ou experiências parecem ser parte fundamental do sintagma lugar de fala que circula amplamente entre as comunidades que produzem discursos antidiscriminatórios e dialoga de certa maneira com a definição de ethos, que veremos a seguir.

O status espontaneamente aceito é mobilizado nos dois enunciados que foram analisados acima. No caso do tuíte, a validação vem do enunciador, que se coloca enquanto homossexual, autorizado a falar da experiência de preconceito nos estádios como torcedor do Palmeiras frente às ofensas feitas aos torcedores do São Paulo, enquanto Casagrande reforça sua validação para comentar esse tema, pois experimentou situações de ofensa na internet, mesmo que seu caso esteja relacionado a outro tipo de preconceito.

Ambos enunciadores procuram legitimação nas experiências vividas frente a discursos discriminatórios. Ao se posicionarem como indivíduos que sofreram preconceito, ambos visam construir um ethos que se sustenta de acordo com suas vivências, porém, "o ethos visado não é necessariamente o ethos produzido." (MAINGUENEAU, 2008a, p. 61), como analisaremos nos enunciados abaixo (figura 2 e figura 3$)^{9}$ procurando responder as seguintes questões:

Filiar-se a um grupo que se identifica como minoria autoriza o sujeito falante a produzir enunciados legitimados sobre todas as minorias? Ou ainda, o discurso de pertencimento pode ser utilizado para silenciar enunciados marcados por preconceitos de diversas ordens?

9 Disponível em: https://oglobo.globo.com/sociedade/professor-de-sp-diz-odiar-pretos-pobresque-falam-alto-comem-de-tudo-22481495. Acesso em: 02 set. 2019. 
Horror de turismo

Odeio pretos e pardos falando muito alto e comendo de tudo por muito tempo, em bandos, nos hotéis três estrelas de orla de praia ! Um café da manhã macabro com tanta algazarra e gulodice. Alguém consegue comer carne de sol com cuscuz logo cedo lotando o prato por 3

Figura 2. Reprodução

Fonte: Facebook

Provavelmente, o ethos visado no enunciado acima corresponde à filiação a uma determinada classe social, na qual os enunciadores são em sua maioria brancos. Entretanto, o enunciador não levou em conta que devido à plataforma de grande alcance (Facebook), seus interlocutores construiriam representações distintas, principalmente por abordar um tema profícuo no campo da polêmica.

É interessante perceber que, na declaração abaixo, o enunciador faz uso de sintagmas como orientação sexual e grupos oprimidos, filiando-se a comunidades antes não mencionadas, visando, mais uma vez, um determinado ethos, porém distinto daquele estabelecido anteriormente.

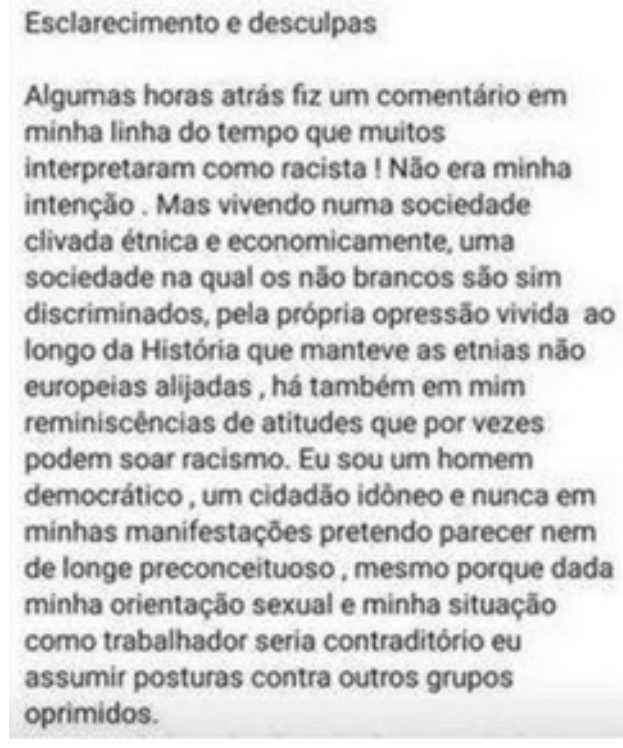

Figura 3. Reprodução

Fonte: Facebook 
A estratégia de construção de uma identidade que se filia a comunidades discursivas específicas, na tentativa de se alcançar um ethos visado também é analisada no enunciado abaixo, que foi retirado de um vídeo ${ }^{10}$ gravado em uma loja do bairro Jardins, em São Paulo, em março de 2018.

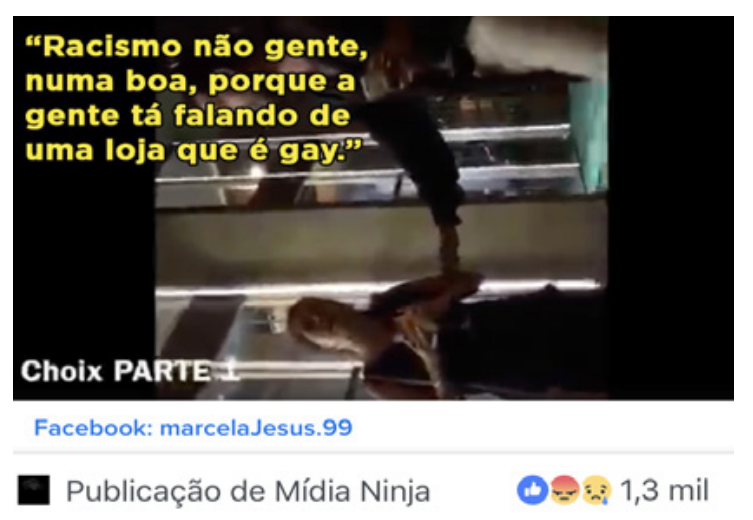

Figura 4. Postagem

Fonte: Facebook de Mídia Ninja

Ao ser confrontado por três jovens negras sobre a acusação de roubo de sabonetes, o funcionário da loja justifica que sua atitude não está relacionada a racismo, pois aquele estabelecimento era gay.

Mais uma vez, convoca-se um pertencimento como estratégia de justificar ou validar o enunciado, retomando uma coletividade ilusória. A identificação com minorias reforça uma imagem de que todos os enunciadores o fazem do mesmo lugar, homogeneizando discursos, suscitando a ideia de que os discursos que circulam são regidos pelo mesmo archeion. Por mais que pensemos os discursos constituintes como delimitadores do lugar comum da coletividade (MAINGUENEAU, 2008a), é preciso atentar para a falácia do discurso único quando se trata de minorias.

O pertencimento a uma minoria (homossexuais) aparece como modo de silenciar o preconceito contra outro grupo (negros) e certos enunciados aqui analisados, figura 3 e figura 4, reforçam o imaginário de que essas comunidades discursivas distintas compartilhariam as mesmas normas e ritos que regem seus discursos.

10 Disponível em: https://www.buzzfeed.com/ramosaline/loja-acusa-jovens-negros-de-roubarsabonete-e-faz-bo-por?utm_term=.IwPr9mYJE\#.gmM7orOGA. Acesso em: 12 ago. 2018. 


\section{Considerações finais}

Para além do discurso político, religioso e de humor, temos um campo fecundo ao analisarmos enunciados nos quais é possível verificar a intenção estratégica de um ethos que visa integrar minorias, produzindo a ilusão de uma comunidade discursiva única, que partilha os mesmos ritos e produz os mesmos discursos.

Esse debate, muitas vezes retomado no emprego do sintagma lugar de fala, produz enunciados polêmicos que permitem uma reflexão sobre a construção da imagem do enunciador em um embate de forças entre diversos discursos, já que "todo ato de tomar a palavra implica a construção de uma imagem de si" (AMOSSY, 2008, p. 9), mas sem esquecer que esse processo não é a construção de um autorretrato e conta com as interpretações e construções que o interlocutor faz do seu alocutário.

Em todos os enunciados apresentados durante essa análise, houve uma tentativa do enunciador de controlar a imagem que o interlocutor construiria dele, buscando validar o ethos visado de acordo com suas experiências, com a finalidade de justificar aquilo que era dito evocando uma identidade. Afınal, "o poder de persuasão de um discurso decorre não somente do que é dito, mas também da maneira de dizer, que é, ao mesmo tempo, uma maneira de ser, uma identidade; e que as diferentes maneiras de ser e de dizer correspondem a mundos éticos bem definidos que as legitimam" (RODRIGUES; SOUZA-E-SILVA, 2012, p. 114).

Quando nos perguntamos "Quem fala?" diante dos enunciados apresentados, obtemos uma resposta sobre o ethos visado do enunciador: "Eu enquanto homossexual..., "Eu enquanto dependente químico...", "Eu enquanto negro...". Para Maingueneau (2008a, p. 65), o ethos também evoca uma corporalidade "apoiando-se em um conjunto difuso de representações sociais, avaliadas positiva ou negativamente, de estereótipos, que a enunciação contribui para reforçar ou transformar". Apesar de essa análise não se debruçar especificamente na construção de estereótipos, é possível afirmar que eles estavam presentes nos enunciados aqui analisados e que, de certa maneira, as representações sociais ligadas a eles possibilitaram o desenvolvimento da análise, pois mobilizaram uma memória discursiva que está atrelada a esta corporalidade.

Tais representações ora retomam o estereótipo para aproximar o ethos visado da construção que o interlocutor tem de si ("eu mesmo, viado e palmeirense"), ora como se o racismo e o preconceito contra homossexuais fossem intercambiáveis, mascarando o próprio estereótipo alimentado pelo preconceito ("racismo não, gente numa boa, porque a gente tá falando de uma loja gay").

Sendo assim, podemos pensar a discussão sobre o emprego dos sintagmas lugar de fala ou politicamente correto, dentro da $A D$, como ponto de um embate polêmico entre 
discursos que inicialmente parecem convergir, mas que em determinado ponto marcam suas distinções, já que têm origem em comunidades discursivas distintas amalgamadas sob o rótulo de minorias.

\section{REFERÊNCIAS}

ALMEIDA, J. A conquista do lugar de fala e fala fora do lugar nos discursos de FHC e Lula sobre o Real. In: RUBIM, A. A. C.; BENTZ, I. M. G.; PINTO, M. J. (org.). Práticas discursivas na cultura contemporânea. São Leopoldo: UNISINOS, 1999.

AMOSSY, R. Imagens de si no discurso: a construção do ethos. São Paulo: Contexto, 2008.

BANDEIRA, G. A.; SEFFNER, F. Futebol, gênero, masculinidade e homofobia: um jogo dentro do jogo. Espaço Plural, n. 29, p. 246-270, 2013. Disponível em: http://www.redalyc. org/html/4459/445944242012/. Acesso em: 10 mar. 2018.

COURTINE, J. J. Análise do Discurso Político. O discurso comunista endereçado aos cristãos. São Paulo. EDUFSCar, 2009.

FILHO, M. O negro no futebol brasileiro. Rio de Janeiro. Mauad, 2010.

FOUCAULT, M. Arqueologia do Saber. 7. ed. Rio de Janeiro. Forense Universitária, 2008.

MAINGUENEAU, D. Cenas da Enunciação. São Paulo. Parábola, 2008a.

MAINGUENEAU, D. Gênese dos discursos. São Paulo. Parábola, 2008b.

MESTI, P. C.; BARONAS, R. L. A (re)construção do ethos discursivo: reflexões sobre as imagens de si em sujeitos em interação. Cad. Est. Ling., Campinas, v. 61, p. 1-13, e019033, 2019. Disponível em: https://periodicos.sbu.unicamp.br/ojs/index.php/cel/article/ view/8655025/21200. Acesso em: 06 set. 2019.

ORLANDI, E. Análise de Discurso. Princípios \& Procedimentos. Campinas: Pontes Editores, 2015.

PALMA, Y. A.; LEVANDOWISK, D. C. Vivências pessoais e familiares de homossexuais femininas. Psicologia em Estudo, Maringá, v. 13, n. 4, p. 771-779, out./dez. 2008. Disponível em: http://www.scielo.br/pdf/pe/v13n4/v13n4a15. Acesso em: 10 mar. 2018. 
PÊCHEUX, M. Semântica e Discurso: uma crítica à afirmação do óbvio. 2. ed. Campinas: Editora da UNICAMP, 2016.

PÊCHEUX, M. Análise de Discurso: Michel Pêcheux. Textos selecionados por Eni Orlandi. 4. ed. Campinas: Pontes Editores, 2014.

POSSENTI, S. A linguagem politicamente correta e a análise do discurso. Estudos Linguísticos, Belo Horizonte, ano 4, v. 2, p. 125-142, jul./dez. 1995.

RODRIGUES, M. G.; SOUZA-E-SILVA, M. C. P. Ethos discursivo e sentidos sobre trabalho no samba. Revista Moara, n. 38, p. 113-125, jul./dez. 2012. Disponível em: https://periodicos. ufpa.br/index.php/moara/article/view/1274/1693. Acesso em: 06 set. 2019.

RUY, L. Homossexualismo e código internacional de doenças. Disponível em: http://www. scielo.br/pdf/rsp/v18n5/02.pdf. Acesso em: 10 mar. 2018.

SALGADO, L. S.; GATTI, M. A. Considerações sobre o sintagma "lugar de fala": um operador de vozes empoderadas? Discurso \& Sociedade, v. 12, n. 3, p. 565-580, 2018. Disponível em: http://www.dissoc.org/ediciones/v12n03/DS12(3)Salgado\&Gatti.pdf. Acesso em: 02 set. 2019. 